\title{
O EMBATE DE FORÇAS TRAVADO DURANTE O PROCESSO DE IMPEACHMENT DE DILMA: UMA ANÁLISE DISCURSIVA DA HETEROGENEIDADE DISCURSIVA ATRAVÉS DA OPERAÇÃO DE NEGAÇÃO
}

\author{
ANDRÊSSA SANTOS GALVÃO (FURG)
}

\begin{abstract}
RESUMO: Este trabalho tem como objetivo discutir o embate de forças travado durante o processo de impeachment da presidenta Dilma, tomando como corpus empírico a sua carta de defesa, enviada ao Senado Federal, em 16 de agosto de 2016; e seu último pronunciamento, enquanto presidenta, em 29 de agosto do referido ano. Para tanto, discute-se, primeiramente, a concepção de Heterogeneidade Discursiva, trazendo pressupostos teóricos de Authier-Révuz e autores que se filiam à Análise de Discurso de filiação pecheuxtiana. Dando seguimento, aborda-se a heterogeneidade discursiva através da operação de negação, a qual surge no discurso de Dilma através de duas operações discursivas, quais sejam: o discurso transverso e o enunciado dividido. É a partir desses dois funcionamentos discursivos que operamos a análise discursiva. Conclui-se, a partir dessa análise, que o embate de forças travado durante o processo de impeachment, fez vir à tona uma discursividade fortemente marcada pelo político, que no discurso de Dilma marca-se a partir da operação de negação.
\end{abstract}

PALAVRAS-CHAVE: Heterogeneidade discursiva. Discurso de Dilma. Negação. Formação-discursiva.

RESUMEN: Este trabajo tiene como objetivo discutir el choque de fuerzas disputado durante el proceso de impeachment de la presidenta Dilma, tomando como corpus empírico su carta de defensa, enviada al Senado Federal, el 16 de agosto de 2016, y su último pronunciamiento, en cuanto presidenta, el 29 de agosto del referido año. Para eso, se discute, primero, la concepción de Heterogeneidad Discursiva, trayendo presupuestos teóricos de Authier-Révus y autores que se filian al Análisis del Discurso de filiación pecheuxtiana. A continuidad, abordase la heterogeneidad discursiva a través de la operación de negación, la cual surge en el discurso de Dilma a través de dos operaciones discursivas, las que son: el discurso transverso y el enunciado dividido. Es a partir de estos dos funcionamientos discursivos que operamos el análisis discursivo. Se concluye, a partir del análisis, que el choque de fuerzas disputado durante el proceso de impeachment, ha traído a la superficie una discursividad fuertemente marcada por el político, que en el discurso de Dilma marcase a partir de la operación de negación.

PALABRAS-CLAVE: Heterogeneidad discursiva. Discurso de Dilma. Negación. Formación-Discursiva.

\section{CONSIDERAÇÕES INICIAIS}

Neste artigo desenvolvemos uma reflexão acerca do discurso de Dilma Vana Rousseff, a qual passou por um processo de impeachment em 2016. Esse processo culminou na destituição de Dilma da Presidência do Brasil. Porém, antes de seu afasta- 


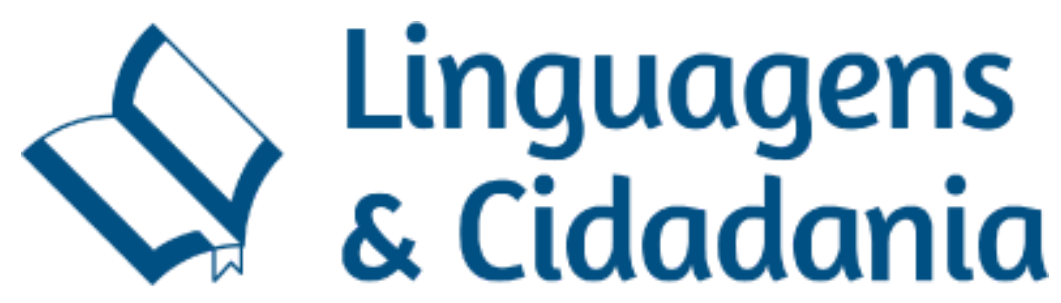

mento definitivo, Dilma escreveu uma carta ${ }^{1}$, enviada ao Senado em 16 de agosto de 2016, e teve a oportunidade de fazer um último pronunciamento, antes do julgamento final, em 29 de agosto do referido ano.

Esse acontecimento histórico gerou agrado e desagrado, dado que de um lado defendia-se a inocência de Dilma; e de outro defendia-se a sua culpa. Além disso, durante o processo, uma forte crise econômica e política se abateu sobre o país, com a deflagração de prisões de políticos e empresários envolvidos em esquemas de corrupção ${ }^{2}$. Acreditamos que, diante desse cenário, o impeachment foi palco de um forte embate de forças que se materializam no discurso de Dilma. Daí entendermos importante analisar seu discurso e refletir sobre os efeitos de sentido produzidos pelo mesmo. Ademais, o impeachment de Dilma deu início a uma série de eventos que determinaram mudanças significativas na política nacional, tal como a ascensão do discurso da extrema direita.

Objetivamos, neste artigo, analisar o embate de forças travado durante 0 processo de impeachment, que no discurso de Dilma se materializa a partir da operação de negação. Tal discurso mostra-se heterogêneo, dado que necessita do discurso-outro para poder materializar o seu, operando a partir de discursos-transversos e a partir de enunciados divididos.

Para Authier-Revuz (2004, p. 12) é no fio do discurso que, real e materialmente, um locutor único produz um certo número de formas, as quais são linguisticamente detectáveis no nível da frase ou do discurso. Tais formas inscrevem em sua linearidade, o outro ${ }^{3}$. Desta forma, entendemos que nossa reflexão é significativa, uma vez que

\footnotetext{
${ }^{1}$ Nosso corpus empírico, portanto, reúne essas duas peças - carta (escrita) e pronunciamento (escrito).

2 Aqui, faz-se menção à Operação Lava Jato, entendida como a maior investigação de corrupção e lavagem de dinheiro que o Brasil já teve. Estima-se que o volume de recursos desviados dos cofres da Petrobras, maior estatal do país, esteja na casa de bilhões de reais. Soma-se a isso a expressão econômica e política dos suspeitos de participar do esquema de corrupção que envolve a companhia. Disponível em: http://lavajato.mpf.mp.br/entenda-o-caso. Acesso em 28 de março de 2017.

${ }^{3}$ Compreendemos que o "outro", para a $\mathrm{AD}$, corresponde ao discurso-outro, que é da ordem do complexo das formações discursivas, ou seja, do interdiscurso, uma vez que o mesmo corresponde ao "isso fala", o "sentido já-lá" (Orlandi, 1990, p. 39) - é a partir da relação entre o intradiscurso com o interdiscurso, que o dizer do sujeito é remetido ao Outro constitutivo (interdiscurso), haja vista que todos os dizeres aí estão.
} 


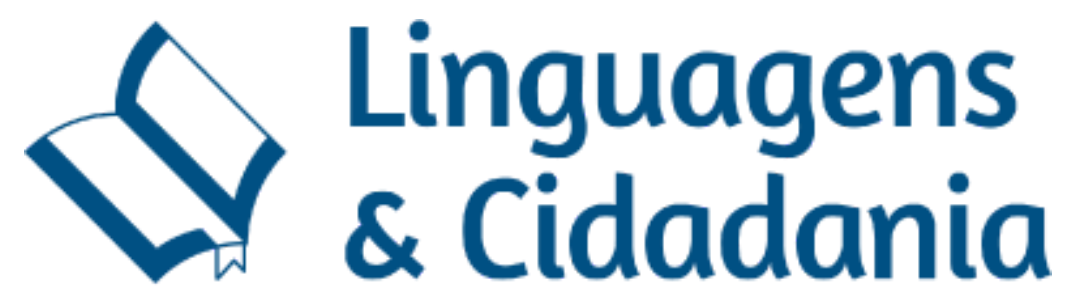

fortalece a concepção de que o discurso de um sujeito não tem origem nele, mas deriva sentidos da memória discursiva. Assim, partimos de Authier-Revuz, pois foi ela que cunhou a noção de heterogeneidade, mas também utilizamos os trabalhos desenvolvidos no âmbito da Análise de discurso de filiação pecheuxtiana (AD), como base para a reflexão que será desenvolvida.

\section{SOBRE A HETEROGENEIDADE DISCURSIVA}

Tendo em vista nosso objetivo principal para este estudo, abordamos neste capítulo algumas considerações acerca da noção de heterogeneidade. Primeiramente, trazemos o que defende Jacqueline Authier-Revuz quanto ao tema, visto que foi quem cunhou a noção, atentando para como a autora concebeu sua teoria; posteriormente, discorremos sobre a noção de heterogeneidade discursiva, no âmbito dos estudos da Análise de Discurso.

Para propor o conceito de "heterogeneidade constitutiva do sujeito e de seu discurso", Authier-Revuz (1990, p. 26) apoia-se na problemática do dialogismo de Bakhtin e na concepção de sujeito e sua relação com a linguagem, considerando os trabalhos de Freud e sua releitura feita por Lacan. A autora propõe uma "descrição da heterogeneidade mostrada como formas linguísticas de representação de diferentes modos de negociação do sujeito falante com a heterogeneidade constitutiva do seu discurso" (AUTHIIER-REVUZ, 1990, p. 26).

Com base nos escritos de Bakhtin, Authier-Revuz apresenta uma releitura do mesmo e articula algumas noções a sua teoria. Segundo a autora (1990, p. 27), para o dialogismo do círculo de Bakhtin "as palavras são, sempre e inevitavelmente, 'as palavras de outros"” e a preocupação central da teoria não é o "diálogo face a face", mas sim uma "dialogização interna do discurso". Dito de outro modo, o sujeito passa a ter as palavras a partir da voz de outrem, já que "nenhuma palavra é neutra, mas carregada, ocupada, habitada, atravessada pelos discursos nos quais viveu sua existência socialmente sustentada". 
No dialogismo de Bakhtin, de acordo com a autora, existe, em termos de interdiscursividade e de interlocução, a inscrição "das palavras dos outros no discurso" (AUTHIER-REVUZ, 2004, p. 68). Isso se dá porque, para Bakhtin, segundo a autora, a interação com o discurso do outro é o que possibilita a constituição do discurso; e é somente por essa via que isso é possível.

Para Authier-Revuz (2004, p. 35-36), o que defende Bakhtin é que o homem olha através das "palavras do outro", isto porque "toda palavra "remete a um contexto, ou a vários, nos quais viveu sua existência socialmente subjugada"”. Ou seja, a palavra advém de outro contexto, porém "penetrada pelo sentido dado por outros".

Assim, Authier-Revuz (2004, p. 36) destaca que o dialogismo é dado como condição de constituição do sentido, pois o discurso se constrói em relação aos outros discursos, sendo os outros discursos "seu exterior constitutivo". De acordo com a autora,

o lugar "do outro discurso" não é ao lado, mas no discurso. Isso posto como lei constitutiva do tecido de todo discurso, não é surpreendente que um campo tenha, de maneira privilegiada, suscitado o interesse do grupo de Bahktin: o das formas que, no nível sintático, discursivo e literário oferecem representações em discurso do discurso outro. (AUTHIER-REVUZ, 2004, p. 37; grifo da autora)

A autora se refere, na citação acima, às formas do discurso relatado, que segundo sua compreensão diz respeito ao "discurso no discurso" e "discurso sobre o discurso". Para Authier-Revuz (2004, p. 38), o ponto de vista dialógico contribuiu para um esclarecimento sobre as formas sintáticas do discurso relatado, sejam elas o discurso direto, o discurso indireto ou ainda o discurso indireto livre.

Segundo essa autora, é importante, ainda, compreender como a interlocução intervém na dialogização interior do discurso, haja vista que

todo discurso é compreendido nos termos do diálogo interno que se instaura entre esse discurso e aquele próprio ao receptor; o interlocutor compreende o discurso através do seu próprio discurso. Visando à compreensão de seu interlocutor, o locutor integra, pois, na produção de seu discurso, uma imagem do "outro discurso", aquele que ele empresta a seu interlocutor. (AUTHIER-REVUZ, 2004, p. 42; grifos da autora) 
Authier-Revuz (2004, p. 44) compreende que a teoria de Bakhtin mostra-se atual, uma vez que "o outro do dialogismo de Bakhtin não é nem um objeto exterior do discurso (falar do discurso do outro), nem o duplo, não menos exterior do locutor", ou seja, o outro do dialogismo é uma condição constitutiva do discurso, é "a condição discurso, e é uma fronteira interior, que marca no discurso a relação constitutiva com o outro" (AUTHIER-REVUZ, 2004, p. 46; grifos da autora).

Authier-Revuz ancora sua teoria no dialogismo de Bakhtin por compreender que a articulação mantida entre "os outros discursos" e "o discurso do outro-interlocutor" são de extrema importância para a compreensão da heterogeneidade discursiva.

A autora ainda ancora seu trabalho na Psicanálise, propondo uma visão do sujeito enquanto entidade heterogênea, uma vez que seu discurso é atravessado pelo inconsciente. Esse sujeito é "resultado de uma estrutura complexa, efeito da linguagem: descentrado, dividido, clivado, barrado..." (AUTHIER-REVUZ, 1990, p.28), pois, em seu discurso,

sempre, as palavras, "outras palavras" são ditas: é a estrutura material da língua que permite que, na linearidade de uma cadeia, se faça escutar a polifonia não intencional de todo discurso, através da qual a análise pode tentar recuperar os indícios da "pontuação do inconsciente". (AUTHIER-REVUZ, 1990, p. 28).

Logo, ao afirmar que, "constitutivamente, no sujeito e no seu discurso está o Outro" (AUTHIER-REVUZ, 1990, p.29), há um reencontro que não pode ser omitido pelas teorias da enunciação: entre as concepções do inconsciente, do discurso e da ideologia. Isto porque esse sujeito é concebido como fragmentado, faltoso, descentrado.

O outro, salienta a autora, "não é um objeto (exterior, do qual se fala), mas uma condição (constitutiva, para que se fale) do discurso de um sujeito falante que não é fonte-primeira desse discurso" (AUTHIER-REVUZ, 2004, p. 69). Portanto, a heterogeneidade constitutiva é não analisável, não localizável e não representável, dada a sua constituição. A autora salienta que

heterogeneidade constitutiva do discurso e heterogeneidade mostrada no discurso representam duas ordens de realidade diferentes: a dos processos reais de constituição dum discurso e a dos processos não menos reais, de 


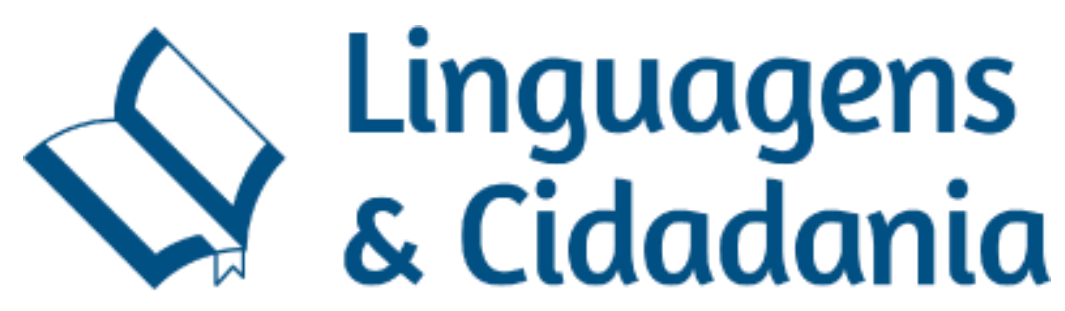

representação, num discurso, de sua constituição. (AUTHIER-REVUZ, 1990, p. 32; grifos nossos)

Quando se trata da heterogeneidade mostrada, o outro se encontra designado como objeto do discurso, através de um mecanismo enunciativo; sua função é manter a ilusão de unidade do discurso. As formas da heterogeneidade mostrada aparecem a partir de marcas, no fio do discurso, "designando o outro localizadamente". Em outras palavras, "ela corresponde a uma função de negociação - necessária - do sujeito falante com essa heterogeneidade constitutiva" (AUTHIER-REVUZ, 2004, p. 72-74).

As formas da heterogeneidade mostrada podem ser marcadas ou não marcadas. Quando marcadas, percebe-se uma ruptura na ordem sintática; quando não marcadas, o fragmento, que é designado como outro, integra-se à cadeia discursiva sem ruptura sintática (AUTHIER-REVUZ, 1990, p. 29-34).

Authier-Revuz (2004, p. 12) inicia a discussão sobre a heterogeneidade mostrada marcada falando sobre o outro do discurso relatado. Para a autora, as formas sintáticas do discurso direto e do discurso indireto marcam um outro ato de enunciação. No discurso indireto, o locutor comporta-se como um tradutor do discurso do outro, fazendo uso de suas palavras, remetendo-o como fonte dos sentidos que ele relata. No discurso direto, o locutor apresenta-se como porta-voz das palavras do outro, ou seja, são as palavras deste que ocupam o tempo e/ou o espaço que é recortado na frase.

As formas não marcadas da heterogeneidade mostrada - discurso indireto livre, ironia... de um lado, metáforas, jogos de palavras, ... de outro lado - representam pelo continuum, a incerteza que caracteriza a referência ao outro, uma outra forma de negociação com a heterogeneidade constitutiva (AUTHIER-REVUZ, 1990, p. 34).

Desta forma, enquanto as formas marcadas dão lugar ao discurso do outro de forma explícita, as formas não marcadas "jogam com a diluição, com a dissolução do outro no um" (AUTHIER-REVUZ, 1990. p. 34), podendo ser este outro enfatizado ou perdido. Como mencionado anteriormente, buscamos, também, referentes teóricos, no âmbito da $\mathrm{AD}$, quanto à noção de heterogeneidade discursiva. Não desconsideramos o 


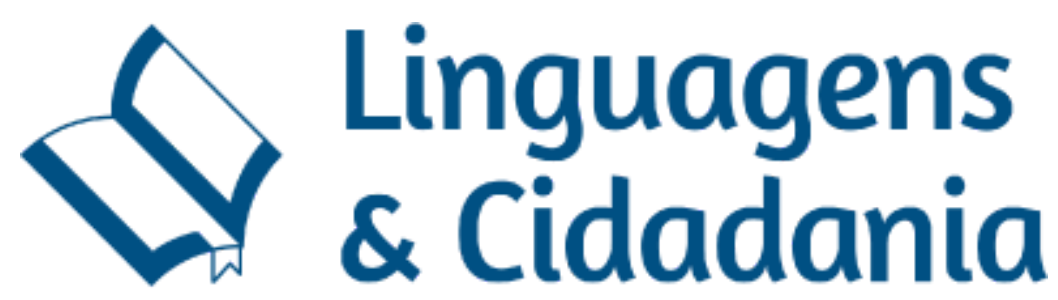

que defende Authier-Revuz, mas, como afirma Orlandi (1990, p. 40), a autora "trabalha muito com a 'formulação'[...] e pouco com a 'constituição' do sentido, ou seja, com a historicidade do discurso no sentido lato (interdiscurso)". E é essa a dimensão que também nos interessa. Nesse sentido, concordamos com Indursky (2013, p. 240) quando chama atenção para a necessidade de romper, através da análise, a aparente homogeneidade discursiva, fazendo vir à tona sua heterogeneidade fundante.

Em “A fala dos quartéis e as outras vozes”, Indursky (2013, p. 240) empreende um estudo a fim de verificar se os discursos presidenciais comportam sequências discursivas heterogêneas e qual a relação que tais discursos estabelecem com o exterior específico e diferente. A autora conclui que no intradiscurso estão intimamente entrelaçados interior e exterior. A partir desse entendimento, é possível dizer que no fio do discurso é possível a articulação entre saberes advindos de Formações Discursivas distintas, as quais podem estabelecer uma relação de aliança ou de antagonismo.

Para compreender a heterogeneidade discursiva no seio da $\mathrm{AD}$, precisamos apreender a concepção de formação discursiva, visto que a própria Formação Discursiva (FD). Pêcheux traz de Foucault a noção de FD. Para Foucault (2008, p. 43), na possibilidade de se descrever, entre um certo número de enunciados, um sistema semelhante de dispersão, e no caso em que entre os objetos, os tipos de enunciação, os conceitos, as escolhas temáticas, seja possível definir uma regularidade, poder-se-á dizer, por convenção, que se trata de uma formação discursiva. Desta forma, a FD, para este autor, apresenta-se como um conjunto de enunciados que se ligam e que se relacionam uns com os outros, colocando em cena determinadas regularidades.

Na Análise de Discurso, essa noção é retomada por Pêcheux associada à teoria das ideologias. Assim, Pêcheux chama de formação discursiva

aquilo que, numa formação ideológica dada, isto é, a partir de uma posição dada numa conjuntura dada, determinada pelo estado da luta de classes, determina o que pode e deve ser dito (articulado sob a forma de uma arenga, de um sermão, de um panfleto, de uma exposição, de um programa etc). (PECHEUX, 2014, p. 147) 


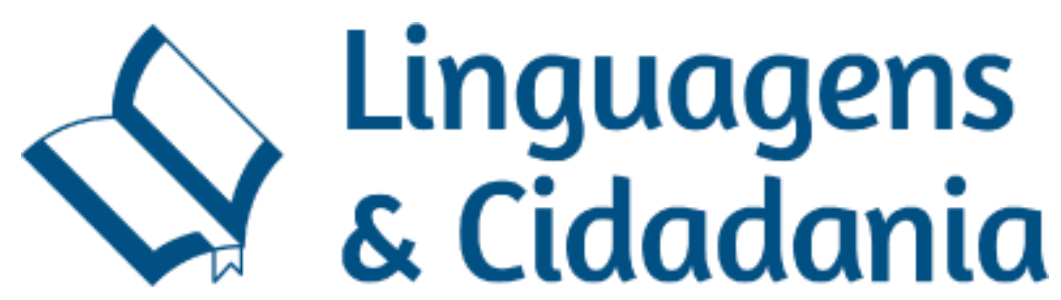

Assim, os sentidos das palavras podem mudar a depender das posições sustentadas por quem as emprega, ou seja, derivam sentido das formações ideológicas em que tais posições se inscrevem. Assim, é possível dizer que na $\mathrm{AD}$, a noção de formação discursiva não é homogênea, pois comporta em seu interior um espaço de transformação.

Dito isso, de acordo com Orlandi (1990, p. 39), "a heterogeneidade coloca em pauta o visível (mostrado), que, na perspectiva do discurso, corresponde ao dizível". Para a autora, o dizível é definido, para o sujeito do discurso, pela relação entre FDs distintas, ou seja, cada domínio de saber determina o que pode e deve ser dito a partir de uma posição dada, em uma conjuntura dada. O complexo das formações discursivas define o universo do dizível, especificando, em suas diferenças, as possibilidades de dizer a partir de determinada posição sujeito (inscrita em uma FD determinada). Assim,

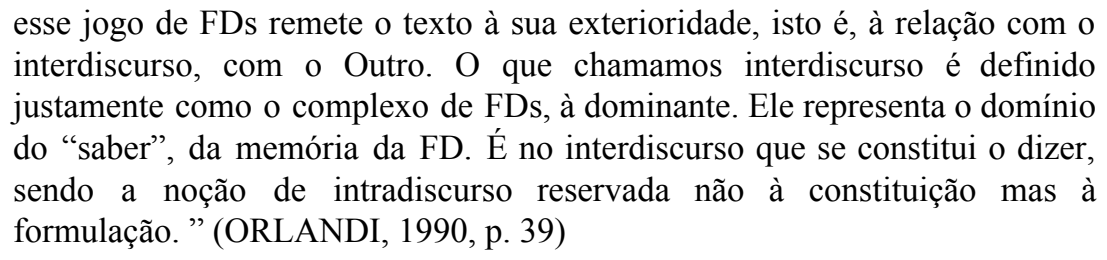

Nessa perspectiva, compreendemos que o "outro", para a $\mathrm{AD}$, corresponde ao discurso-outro, que é da ordem do complexo das formações discursivas, ou seja, do interdiscurso, uma vez que o mesmo corresponde ao "isso fala", o "sentido já-lá" (Orlandi, 1990, p. 39) - é a partir da relação entre o intradiscurso com o interdiscurso, que o dizer do sujeito é remetido ao Outro constitutivo (interdiscurso), haja vista que todos os dizeres aí estão.

Segundo Orlandi (1990, p. 40), a heterogeneidade em Authier-Revuz é concebida "como uma mistura $(\mathrm{a}+\mathrm{b})$, sendo a e b distintos e recuperáveis". Em contrapartida, na $\mathrm{AD}$, há uma combinação entre a e b, não sendo possível recuperar a origem de ambos. Assim,

são só efeitos que estão lá. Não se detectam os elementos como componentes (a e b); se os reconstrói pelo jogo das diferentes formações discursivas. Logo, a ilusão só é dizível pela teoria e não pelas marcas, pois a heterogeneidade 
constitutiva não é representável, já que ela é do escopo do interdiscurso. (ORLANDI, 1990, p. 40)

Dessa forma, é possível, a partir do dizível, compreender não o que não se diz, mas o dizer do outro no um, a partir da relação entre as formações discursivas. É nesse jogo entre as FDs que o texto é remetido ao seu exterior, à relação que esse estabelece com o interdiscurso (ORLANDI, 1990, p. 39).

Mittmann destaca que a noção de heterogeneidade discursiva, para a $\mathrm{AD}$, não se limita a descrever as relações internas de costura evidente de vozes, nem ao trabalho cognitivo entre locutor e alocutário na busca da uniformidade, nem a instruções para descrição da enunciação. (MITTMANN, 2005, p. 86). Para a autora, observar o atravessamento eventual da voz de um outro identificável no discurso do um só serve à teoria como um passo a mais no caminho para a discussão sobre as condições de produção do discurso, as relações de força, as relações de sentido, os conflitos fronteiriços e as contradições internas das formações. (MITTMANN, 2005, p. 86)

O que nos interessa, sobremaneira, não é marcar onde começa um discurso e onde termina outro, mas sim o que estabelece Mittmann, ao final da citação acima: as condições de produção, as relações de força, as relações de sentido, os conflitos fronteiriços e as contradições internas das formações discursivas que são postas em cena.

\section{A HETEROGENEIDADE ATRAVÉS DA OPERAÇÃO DE NEGAÇÃO}

O discurso-outro, além das formas do discurso relatado, pode irromper por meio de uma operação de negação. Note-se que nos casos analisados este funcionamento discursivo implica dois funcionamentos discursivos que muito nos interessam, quais sejam: o discurso transverso e o enunciado dividido. Dessa forma, o sujeito do discurso opera, via negação, dois funcionamentos discursivos que trazem para o fio do discurso o discurso do outro.

Em “A fala dos quartéis e as outras vozes", Indursky (2013, p. 261) assinala que a partir da negação é possível “investigar a presença do pré-construído como vestígio mais ou menos evidente do interdiscurso no discurso presidencial”, ou seja, há uma “internalização de enunciados oriundos de outros discursos". No entender da autora, tra- 
ta-se de "um discurso que se constrói na base de uma relação polêmica e de antítese em relação com o outro." (INDURSKY, 2013, p. 265). Logo, a partir dessa construção é possível apreender o discurso-outro no interior do discurso em análise. Segundo a autora,

quando o sujeito do discurso pode e deve dizer o que diz a partir do seu lugar social, ele o faz por uma predicação afirmativa, identificando seu dizer com o saber da FD que o afeta. Já quando sua predicação é negativa, esta pode caracterizar três operações de negação discursiva diversas: a negação externa... a negação interna... e a negação mista. (INDURSKY, 2013, p. 264)

Nesta pesquisa, interessa-nos a operação de negação do tipo externa, visto que esta ocorre de maneira expressiva no discurso em pauta. Nessa modalidade, há a ocorrência do que Indursky (2013, p. 266-267) chama de "negação do discurso do outro", em que a marca de negação é explícita, enquanto o discurso do outro é implícito. É o que a autora compreende como "discurso da implicitação", pois D1 ${ }^{4}$ constitui-se a partir de tal modalidade da negação, uma vez que, ao negar D2 (que está implicitado), transforma o discurso do outro em seu contrário e o incorpora.

De acordo com Indursky (2013, p. 266), a modalidade de negação externa apresenta dois tipos diversos: negação do discurso do outro e negação do pré-construído do discurso do outro. No nosso estudo, ocorre a negação do discurso do outro, daí discutirmos somente esse tipo de negação externa.

A negação, segundo Cazarin (1998, p. 97), apresenta-se como um tipo de "heterogeneidade discursiva mostrada marcada", pois

o não funciona como marca de que no interdiscurso existe um enunciado afirmativo próprio da FD2, possível de ser recuperado através da categoria da memória discursiva. O sujeito do discurso recupera, no interdiscurso, o discurso-outro, insere-o no seu discurso de forma negativa, o que lhe abre espaço à apresentação de um outro discurso, próprio de sua FD (CAZARIN, 1998, p. 97).

\footnotetext{
${ }^{4}$ Para fins de compreensão, compreende-se como D1 - O discurso representativo da posição-sujeito que se inscreve na FD Interna; e D2 - O discurso representativo da posição-sujeito que se inscreve na FD Externa. A FD Interna é compreendida como o domínio de saber que comporta o discurso governamental e de seus aliados; e a FD Externa como domínio de saber que comporta o discurso não governamental, representativa de forças políticas e sociais que se opõem ao governo Dilma.
} 
A recuperação do discurso-outro, portanto, se dá pelo viés da negação, a qual possibilita que se apresente um outro enunciado, o qual corresponde a pré-construídos que são articulados ao discurso em pauta sob a modalidade do discurso transverso.

Para falar sobre a noção de pré-construído, Pêcheux retoma a concepção de Henry, o qual a entende como algo que "remete a uma construção anterior, exterior, mas sempre independente, em oposição ao que é ‘construído' pelo enunciado.” (PÊCHEUX, 2014, p. 89).

Segundo Courtine,

o interdiscurso funciona [...] como um discurso transverso, a partir do qual se realiza a articulação com o que o sujeito enunciador dá coerência "ao fio de seu discurso": o intradiscurso de uma sequência discursiva aparece nessa perspectiva como um efeito do interdiscurso sobre si próprio. (2009, p. 75; grifos do autor)

Assim, o interdiscurso fornece os objetos dos quais o sujeito se apropria, atravessando a enunciação de uma sequência discursiva e conectando entre si esses objetos, apagando, assim, as marcas de sua procedência. De acordo com Indursky (2013, p. 271-272), apesar da aparente homogeneidade que tal funcionamento discursivo produz, é possível, a partir da operação de negação do discurso do outro, um discurso veicular em seu interior dois enunciados contrários, afetados por FDs contrárias, isto é, a partir de tal modalidade de negação o enunciado apresenta-se dividido.

Este funcionamento discursivo traz para o fio do discurso o discurso-outro e coloca em confronto discursos antagônicos que funcionam num mesmo enunciado, ou seja, irrompe no discurso de Dilma, também, pelo viés do enunciado dividido, uma vez que esse põe em cena discursos de diferentes FDs. Isto é, a partir da concepção do que seja um enunciado dividido, é possível compreender o embate entre discursos antagônicos, os quais colocam em cena o discurso-outro.

Para Courtine (2009, p. 193), a expressão P X/Y materializa, no interdiscurso, a fronteira dos domínios de saber próprios a FDs antagônicas, ou seja, indica a linha divisória entre o formulável e o não formulável de acordo com os processos discursivos 


\section{W. Linguagens}

em cuja articulação contraditória tal fronteira se materializa. Desta forma, essa linha divisória, determina os elementos do saber de uma FD, mas também, de uma FD antagônica.

Com base nesse entendimento, Courtine nomeou essa estrutura como "enunciado dividido" (COURTINE, 2009, p. 194), ou seja, existem elementos que assumem um valor antagônico no interior do processo discursivo, não podendo ser comutáveis, visto que convivem em confronto no mesmo enunciado. Tais elementos antagônicos estão dispersos no interdiscurso, e só podem ser apreendidos a partir da categoria da memória discursiva, permitindo, assim, que se acione a conjuntura histórico-social em que ocorreu o discurso em pauta (CAZARIN, 1998, p. 93).

Cazarin (1998, p. 93), ao analisar a heterogeneidade discursiva mostrada (marcada ou não) no discurso político de L. I. Lula da Silva, elenca uma série de marcas linguísticas que evidenciam o confronto entre FDs antagônicas, tais como: "não é X...mas é Y; não...frase afirmativa; jamais...frase afirmativa; nunca...frase afirmativa; não é só X...é Y; se é verdade que X... também é verdade que Y”. É nesta perspectiva que pretendemos operar nosso corpus analítico, buscando marcas que indiquem um confronto entre FDs, a partir de discursos transversos e de enunciados divididos, marcando, assim, a heterogeneidade discursiva do discurso em pauta.

\subsection{O discurso transverso pelo viés da negação}

Nos ocupamos, neste sub-capítulo, em compreender como a operação de negação do discurso do outro traz consigo um discurso transverso. Dado que estamos nos ocupando de um discurso de autodefesa, é perceptível a recorrência da negação na tentativa desse sujeito desqualificar o discurso-outro para comprovar sua inocência. Abaixo, apresentamos três sequências discursivas extraídas do discurso da presidenta:

SD1: Um momento que não tolera omissões, enganos, ou falta de compromisso com o país. (CARTA)

SD2: Não traio os compromissos que assumo, os princípios que defendo ou os que lutam ao meu lado. (PRONUNCIAMENTO) 


\section{$\checkmark$ Linguagens \& Cidadania}

SD3: Hoje, quatro décadas depois, não há prisão ilegal, não há tortura, meus julgadores chegaram aqui pelo mesmo voto popular que me conduziu à Presidência. (PRONUNCIAMENTO)

A fim de analisar essas sequências discursivas, isolamos o discurso-outro, visto que esse não é explicitado. Para tal, "é preciso transformar metodologicamente a negação em afirmação", como propõe Indursky (2013, p. 268; grifos da autora), uma vez que, somente assim o discurso do sujeito de D2, que está implícito em D1, pode ser tangenciado. Tais transformações, salientamos, resultam em enunciados representativos da FDE. Vejamos:

SD1: Dilma tolera omissões, enganos, ou falta de compromisso.

SD2: Dilma trai os compromissos que assume, os princípios que defende, bem como os que lutam ao seu lado.

SD3: Prisão ilegal e tortura são permitidos.

$\mathrm{Na}$ SD1, o sujeito nega o discurso de D2, tangenciando o que é permitido circular no interior de sua FD. Ao negar, o discurso-outro, esse atravessa transversalmente o discurso de D1. Nessa perspectiva, "Omissões, enganos ou falta de compromisso" são saberes interditados ideologicamente no interior da FDI, isto é, o sujeito de D1 traz para o seu discurso, via negação, saberes que circulam na FDE. São pré-construídos que se articulam ao discurso de D1, por meio de um discurso transverso. Dessa forma, o discurso de D1 traz consigo um discurso ao qual se opõe. Segundo Cazarin, neste funcionamento discursivo

\footnotetext{
o discurso-outro é inserido, no discurso da FD1, mas, como consiste naquilo que é interditado nessa FD, aí comparece através de uma operação de negação e não é explicitado. Trata-se de uma negação do discurso-outro, na qual a sd (sic) não apresenta de forma explícita dois enunciados antagônicos como ocorre no enunciado dividido. (1998, p. 105)
}

$\mathrm{Na}$ SD2, por exemplo, temos um discurso que circulou na exterioridade da FDI, bem como a ideologia que está na base da FDI. Ao negar o discurso do outro (SD13), o sujeito de D1 afirma quais são os dizeres ideologicamente pertencentes à sua FD. Dito de outra maneira: o discurso-outro faz eco no discurso de D1, atravessando-o transversalmente. Temos, portanto, "a internalização transversa" do discurso-outro (INDURSKY, 2013, p. 270). Isso porque, segundo Indursky, a operação de negação coloca em pauta o que chama de "jogo dos contrários", já que "revela a presença 


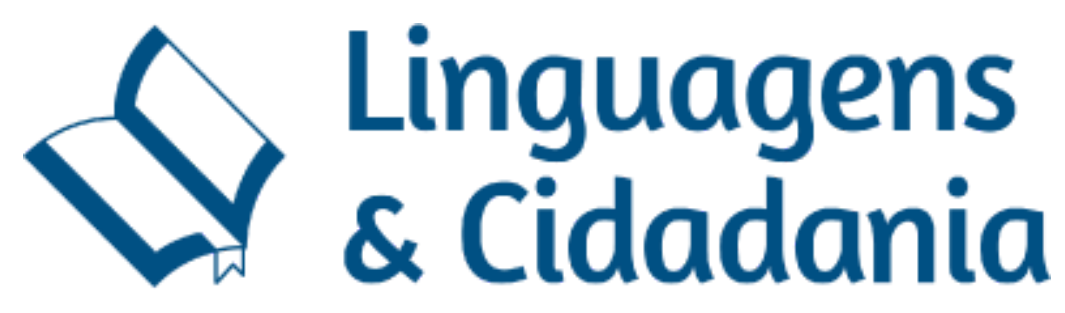

transversa do discurso do outro" (INDURSKY, 2013, p. 270; grifos da autora). Nesse sentido, a negação coloca em confronto discursos pertencentes a FDs antagônicas, discursos que são inconciliáveis. Isto é dizer que o sujeito, ao refutar um elemento do saber de outra FD, refuta, também, um elemento que é exterior ao saber de sua FD (INDURSKY, 1990, p. 119).

Ao negar o discurso de D2, o sujeito de D1, além de afirmar o que circula na FDI, projeta-se no discurso como comprometido. Nosso entendimento é de que o sujeito de D1 nega o discurso do outro e afirma-se como um sujeito que tem compromisso; respondendo, assim, à seguinte pergunta: "quem sou eu para que ele me fale assim".

Se como entende Cazarin (2004, p. 49), o discurso político a fim de facilitar a ação política, pode legitimá-la, podemos concluir que estamos diante de um discurso fortemente afetado pelo político, visto que o sujeito de D1 desqualifica o que diz o sujeito de D2 e afirma que os saberes que circulam na FDI são legítimos.

Na SD3, temos uma referência a um discurso-outro de extrema importância, haja vista o histórico da presidenta Dilma. Entre os anos de 1970 e 1972, Dilma foi mantida em cárcere e sofreu tortura, por determinação da Ditadura instaurada. Na sua carta ao Senado e durante sua defesa, a presidenta faz referência a este período. Aqui, há uma negação que determina o que pode e deve ser dito (ou o que não pode e não deve ser dito) no âmbito de sua FD.

Neste caso, temos a negação do discurso da Ditadura que teve ações que ainda ressoam na atualidade. O que percebemos é que o discurso da FDI se baseia em Leis que foram outorgadas após a Ditadura e ainda na experiência vivida pelo sujeito do discurso. Logo, "prisões ilegais" e "tortura" são saberes provenientes de uma FDE que antagonizam com saberes da FDI, daí a necessidade de negar esses saberes e tangenciar o que é permitido no âmbito da FDI.

Ao negar o Discurso da Ditadura, o sujeito de D1 chama atenção para saberes que somente são permitidos em uma FD que apoia a Ditadura. Chegamos a esta conclusão pela categoria da memória discursiva, a partir da qual retornamos a esses 
saberes. Essa negação ainda nos leva a compreender como o sujeito de D1 é afetado pela história da Ditadura, uma vez que carrega em seu corpo as marcas da violência sofrida; e isto irrompe no fio do discurso, sendo negado e relegado a outra FD que não a sua. Desta forma, "aquilo que é afirmado na FD externa transforma-se em "não-dito" na FD interna" (CAZARIN, 1998, p. 106), ou seja, a instauração do discurso da FDI se dá à medida que o sujeito de $\mathrm{D} 1$ repudia o dito da FDE, que se materializa no discurso a partir de uma operação de negação.

Indursky (1990, p. 119) entende que "o sujeito, ao construir seu discurso, incorpora enunciados pré-construídos", os quais ao serem introduzidos no intradiscurso, causam o esquecimento de que foram incorporados e produzem o "efeito de ali se originarem". Trata-se de saberes já-ditos em outro discurso, em outro lugar, que ressoa no discurso do sujeito, ou seja, “o discurso-outro entra de viés no discurso do sujeito, tangenciando-o e nele fazendo eco de algo que foi dito em outro lugar". Para essa mesma autora, a negação instaura a polêmica no interior do discurso, uma vez que

a polêmica aí se instaura porque tais pontos de vista representam posições de sujeito determinadas por $\mathrm{FD}$ antagônicas [...] em $\mathrm{AD}$, a relação polêmica não se estabelece diretamente entre dois sujeitos, mas entre duas posições de sujeito que representam FD antagônicas. (INDURSKY, 1990, p.119)

Nos casos analisados, a operação da negação lineariza um pré-construído sob a modalidade do discurso transverso. Ou seja, "retoma um pré-construído que foi objeto de asserção em outro lugar e que, no discurso que dele se apropria, ressoa metonimicamente, como um implícito" (INDURSKY, 2011, p. 70). Isto é, o discurso-outro que circula na FDE articula-se ao discurso de D1, produzindo um efeito de homogeneidade discursiva. Portanto,

o interdiscurso enquanto discurso-transverso atravessa e põe em conexão entre si elementos discursivos constituídos pelo interdiscurso enquanto pré-construído, que fornece, por assim dizer, a matéria-prima na qual o sujeito se constitui como "sujeito falante", com a formação discursiva que o assujeita. Nesse sentido, pode-se bem dizer que o intradiscurso, enquanto "fio do discurso" do sujeito, é, a rigor, um efeito do interdiscurso sobre si mesmo, uma "interioridade" inteiramente determinada como tal "do exterior". (PÊCHEUX, 2014, p. 154) 


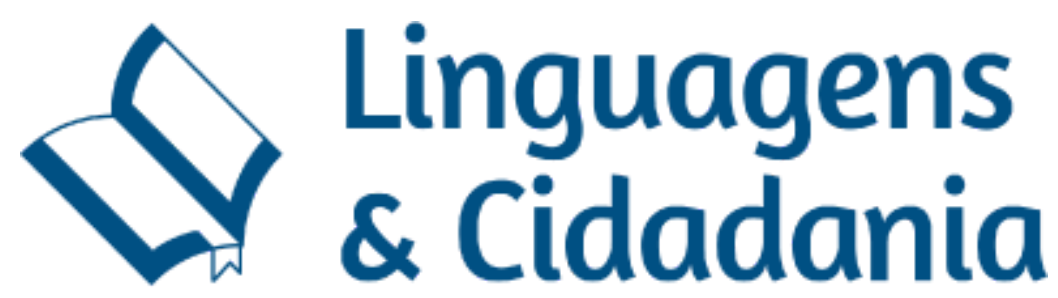

Isto é dizer que o discurso-transverso atravessa o discurso do sujeito de D1, dando uma aparência de homogeneidade ao seu discurso, de unidade. Pode-se dizer que o sujeito de D1 se apropria de saberes advindos do interdiscurso, articulando-os ao seu discurso, causando a impressão de terem sido produzidos ali, e não em outro lugar. Acreditamos, ainda, que o sujeito de D1 precisa refutar, a partir da operação de negação, o discurso do outro, o dito de D2. Ao fazê-lo traz do interdiscurso, via discurso transverso, saberes da FDE. É negando tal discurso, que o sujeito de D1 afirma-se como pertencente a uma FD antagônica, bem como marca que há confronto entre seu discurso e o que está implícito no seu discurso. Nas palavras de Indursky:

o discurso-outro, não podendo ser dito pelo sujeito de D1, passa a constituir o indizível desse discurso que permanece, para sempre, recalcado em seu interdiscurso específico. É o discurso da implicitação. Ou seja, D1 constitui-se na modalidade negativa, negando D2, que está implicitado. Seu funcionamento transforma o discurso do outro em seu contrário e como tal o incorpora. (2013, p. 267).

Segundo Authier-Revuz (1990, p. 33), “as formas marcadas da heterogeneidade mostrada asseguram esse "eu [...] dando corpo ao discurso", a partir das fronteiras que demarcam, dando forma, ainda, ao sujeito do discurso. Isto é, ao negar o discurso do outro, o sujeito de D1 dá corpo ao seu discurso, e ao que pertence a sua FD.

Nessa perspectiva, a operação da negação do discurso do outro causa o efeito de homogeneidade discursiva, uma vez que esta modalidade de inserção do discurso-outro traz consigo pré-construídos que são articulados ao seu enunciado sob a modalidade do discurso transverso, causando a impressão de que foram produzidos ali. Isto é dizer que o sujeito esquece que já foi dito e crê-se fonte do sentido, porém, seu discurso faz eco de algo que fora dito antes, em outro lugar, em outras condições de produção. Tal compreensão nos leva a entender o discurso da presidenta como heterogêneo.

\subsection{O enunciado dividido pelo viés da negação}

No capítulo anterior, analisamos o discurso-outro pelo viés do discurso transverso, ou seja, o discurso do outro dissimulado no interior do discurso da 
presidenta. Interessa-nos, aqui, compreender como o discurso-outro se lineariza pelo viés da negação, colocando em confronto enunciados pertencentes a FDs antagônicas, isto é, ainda estamos diante da operação de negação do discurso do outro, porém, nos casos que analisamos a seguir, há uma reversão do discurso-outro para a FDI, via enunciado dividido. Abaixo, elencamos quatro sequências discursivas que serão analisadas.

SD4: No presidencialismo previsto em nossa Constituição, não basta a desconfiança política para afastar um Presidente. Há que se configurar crime de responsabilidade. (CARTA; linhas 15-16)

SD5: Não é legítimo, como querem os meus acusadores, afastar o chefe de governo pelo "conjunto da obra". Quem afasta o presidente pelo "conjunto da obra" é o povo, e só o povo, nas eleições. (CARTA; linhas 18-20)

SD6: Não luto pelo meu mandato por vaidade ou por apego ao poder, como é próprio dos que não tem caráter, princípios ou utopias a conquistar. Luto pela democracia, pela verdade e pela justiça. Luto pelo povo do meu país, pelo seu bem-estar. (PRONUNCIAMENTO; linhas 42-45)

SD7: O que está em jogo no processo de impeachment não é apenas o meu mandato. $\mathrm{O}$ que está em jogo é o respeito às urnas, à vontade soberana do povo brasileiro e à Constituição. (PRONUNCIAMENTO; linhas 92-93)

Na SD4, percebemos uma marca de negação explícita que, segundo Indursky (2013, p. 266-267), diz respeito à negação do tipo externa. Assim como no sub-recorte anterior, o discurso do outro não é explicitado, para percebê-lo é preciso isolá-lo, transformando a negação em afirmação. Dito de outra maneira: o funcionamento discursivo é outro, mas o efeito de sentido produzido é o mesmo da negação do discurso do outro. Assim, é necessário tangenciar o discurso-outro que está implicitado. Para fins de análise, faremos o que orienta Indursky (2013, p. 268), transformando em afirmação o que é negado.

FDE: A desconfiança política basta para afastar um presidente.

FDI: Para afastar uma presidenta é preciso a configuração de crime de responsabilidade.

Assim, temos o surgimento de um discurso pertencente à FDE, que é negado pelo sujeito de D1. Note-se que após a negativa há uma afirmação, a qual acreditamos ser pertencente à FDI. Temos, então, a forma "Não basta X... É preciso Y", configurando um enunciado dividido. 


\section{Q. Linguagens}

De acordo com Indursky (2013, p. 272), sob a aparente unidade, o enunciado dividido coloca em pauta dois enunciados contrários afetados por FDs antagônicas, que indicam posições de sujeito inconciliáveis. Assim, a partir da modalidade do enunciado dividido, temos duas FDs que antagonizam entre si, marcadas pela forma "não ... frase afirmativa", isto é, a negação do discurso advindo da FDE e a afirmação do discurso proveniente da FDI. Portanto, temos FDs que antagonizam entre si, marcando uma tensão no interior do enunciado. De acordo com Cazarin (1998, p. 97), nesse funcionamento discursivo "o sujeito do discurso recupera, no interdiscurso, o discurso-outro, insere-o no seu discurso de forma negativa, o que lhe abre espaço à apresentação de um outro discurso, próprio de sua FD”.

A SD5 apresenta-se, também, sob a modalidade do enunciado dividido. Porém, neste caso, além da negação do discurso do outro, há o uso das aspas, que segundo Authier-Revuz (2004, p. 13) indica um fragmento que "recebe, em relação ao resto do discurso, um estatuto outro.”. Portanto, as aspas, indicam que algo vem de fora, de outro lugar, ou seja, do interdiscurso. Vejamos como se desdobra esse discurso:

FDE: Afastar o chefe de governo pelo conjunto da obra é legítimo.

FDI: Afastar o chefe de governo pelo "conjunto da obra" é inconstitucional.

A partir dessa transformação metodológica, é possível dizer que o discurso de D2, irrompe, trasnversalmente o discurso de D1, a partir da operação de negação. Assim, o sujeito de D1 busca desqualificar o discurso de D2 e afirmar o seu. Segundo Cazarin (1998, p. 97), tal funcionamento discursivo marca-se por uma operação de afirmação/negação/afirmação, ou seja, temos saberes que são afirmados na FDE, e negados na FDI, havendo, ainda, uma reversão desses saberes para o que é permitido circular na FDI. Assim, é preciso que o sujeito de D1 desqualifique o discurso do outro para afirmar o seu. E, ao afirmar o seu discurso, o sujeito delimita o que é permitido circular no interior da sua FD, bem como a ideologia que lhe subjaz.

Compreendemos, ainda, que o sujeito de D1, apesar de antagonizar com o que circula na FDE, delimita o espaço em que tal elemento pode ser mobilizado, bem como 


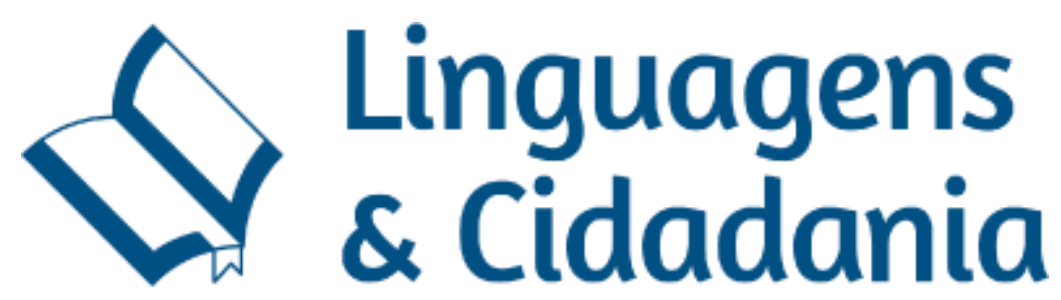

quem pode mobilizá-lo, ou seja, somente o povo, tem o direito de afastar um presidente pelo "conjunto da obra". É dizer: tal saber tem legitimidade a depender das condições de produção. Ao marcar com as aspas o elemento "conjunto da obra" o sujeito de D1 marca uma fronteira entre o que é permitido circular no interior de sua FD, porém, acreditamos que, no fio do discurso, tal elemento ganha aparência de legitimidade a depender das condições de sua produção.

O sujeito de D1 além de desqualificar o discurso-outro também o refuta. Veja-se o caso da SD6, em que a operação de negação aparece a partir da seguinte forma: "Não luto por X, (mas) luto por Y". Ao transformarmos em afirmação esse enunciado, podemos perceber o surgimento de um outro. Vejamos:

FDE: Dilma luta por seu mandato por vaidade ou apego ao poder.

FDI: Dilma luta pela democracia, pela verdade, pela justiça, pelo povo e pelo seu bem-estar.

Neste caso, temos, novamente, um enunciado dividido, ou seja, a existência, no intradiscurso, de enunciados contrastivos, pertencentes a FDs antagônicas. No mesmo enunciado, podemos identificar, ainda, posições de sujeito contrárias, dado que o discurso-outro comporta uma série de questões que antagonizam com o discurso da FDI.

Lutar por vaidade ou por apreço ao poder não pode estabelecer uma relação de aliança com o que vem posteriormente: democracia, justiça, verdade e bem-estar do povo. Desta forma, podemos dizer que, apesar da aparente unidade do enunciado, este apresenta em seu interior saberes provenientes de FDs antagônicas. Ao utilizar a negação, o sujeito de D1 faz uma reversão dos saberes da FDE para a FDI, evidenciando um conflito e uma tensão no interior do enunciado. Ademais, compreendemos que o sujeito de D1 se projeta no discurso como democrático, isto é, afirma-se como um sujeito que preza determinadas características que se opõe ao que diz o sujeito de D2. 


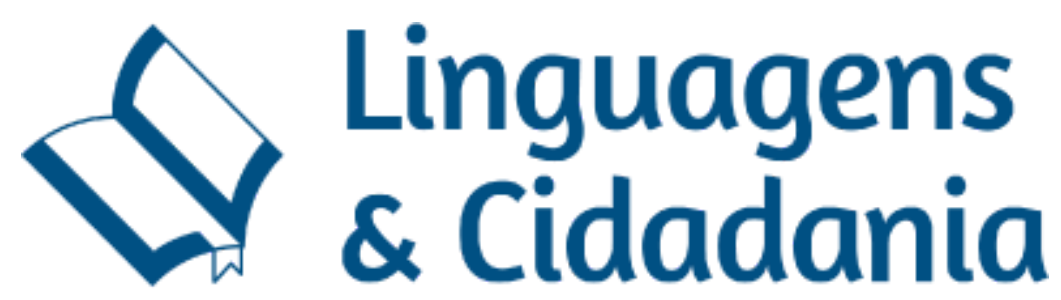

Na sequência que segue (SD7), temos um enunciado dividido que se apresenta sob a seguinte fórmula: não é apenas X... é Y. De acordo com Cazarin (1998, p.98), é "uma outra forma de dizer um enunciado dividido, através da qual o sujeito do discurso busca mostrar a insuficiência do discurso da FD externa". Vejamos como se desdobra esse enunciado:

FDE: O que está em jogo no processo de impeachment é apenas o mandato da presidente Dilma.

FDI: O que está em jogo no processo de impeachment é o meu mandato, o respeito às urnas, à vontade soberana do povo e à Constituição.

O sujeito de D1 afirma que o que está em jogo, não é somente o que afirma o sujeito de D2 "o mandato da presidente", mas também "o respeito às urnas, à vontade soberana do povo e à Constituição". Nesse tipo de construção do enunciado dividido há a possibilidade de o sujeito de D1, "lançar mão de uma construção linguística que lhe permite fazer acréscimos a esse discurso" (CAZARIN, 1998, p. 99).

Desta forma, o sujeito de D1, desqualifica o discurso de D2, julga-o insuficiente, e o contrapõe. Nessa perspectiva, coloca-se em pauta o que de fato "está em jogo", marcando que o discurso que circula na FDE não é único nem definitivo. Cazarin assinala que "a partir da colocação de Y, X é considerado "pobre", insuficiente, perdendo o caráter de exclusividade" (CAZARIN, 1998, p. 100). Acreditamos que, a partir dessa construção do enunciado dividido, o efeito de sentido produzido é o de crítica ao caráter restritivo do discurso-outro, ou seja, não há uma rejeição total desse, mas sim a sua desqualificação, por esse se mostrar insuficiente. Tal funcionamento discursivo instaura a polêmica no interior do enunciado, marcando assim, uma tensão entre forças antagônicas, ou seja, um forte embate entre FDs que antagonizam entre si.

Neste sub-capítulo, acreditamos ser possível dizer que o sujeito de D1 confronta os saberes provenientes da FDE. Para tanto, a partir da operação de negação, rejeita o discurso-outro, desqualificando-o e reorientando o discurso para o que, a partir de sua posição-sujeito, é permitido circular ou não na sua FD.

\section{PRODUZINDO UM EFEITO DE FECHAMENTO}




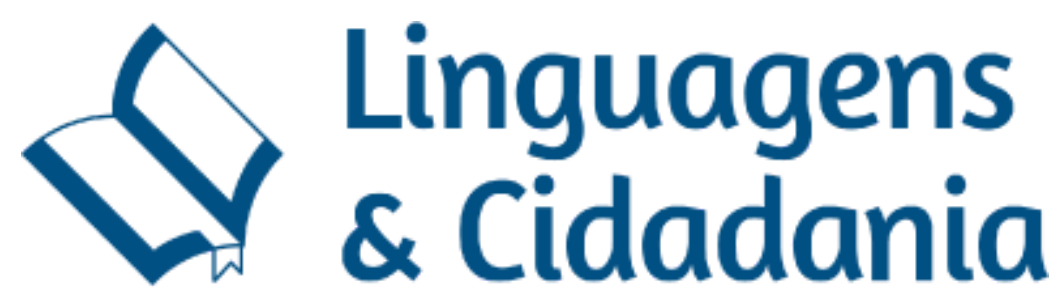

Concluímos que os funcionamentos discursivos analisados são marcados por um forte embate entre forças antagônicas, isto é, uma relação de confronto entre FDs antagônicas (FDI-FDE). Porém, para cada funcionamento discursivo, essa relação se lineariza de maneira distinta, ou seja, funciona, discursivamente, de forma diversa.

A operação de negação, de acordo com nossas análises, lineariza um pré-construído no discurso de D1. No discurso transverso pelo viés da negação, o discurso-outro atravessa transversalmente o discurso de D1, a partir de uma negação explícita; já no segundo recorte, além de o discurso-outro atravessar o discurso de D1, temos enunciados contrastivos num mesmo enunciado, caracterizando um enunciado dividido.

O funcionamento discursivo, operado a partir da negação, coloca em confronto FDs antagônicas, estabelecendo um forte embate entre forças que antagonizam entre si. Tal funcionamento discursivo produz um efeito de sentido de rejeição do discurso do outro, além de um efeito de homogeneidade discursiva, uma vez que o discurso do outro não está explícito, sendo recuperável a partir de uma transformação metodológica.

O sujeito do discurso projeta-se como comprometido (O discurso transverso pelo viés da negação); e democrático (e $\mathrm{O}$ enunciado dividido através da negação). Apesar de tal discurso ser heterogêneo, é importante chamar atenção para a ilusão que o sujeito do discurso tem sobre a homogeneidade de seu discurso. Isso porque, ao relatar o discurso do outro ou negá-lo, há uma ilusão de que o discurso de que se ocupa o sujeito de D1 é homogêneo. Todavia, entendemos que toda fala é fundamentalmente heterogênea, uma vez que o sujeito do discurso recorre ao discurso do outro para constituir o seu.

No discurso que analisamos, concluímos que o político se apresenta sob a forma da divisão, ou seja, sob a aparente unidade do discurso há discursos se confrontando, marcando um forte embate entre forças, as quais disputam um espaço num cenário político. Daí afirmarmos que o discurso de Dilma é fortemente afetado pelo político. 


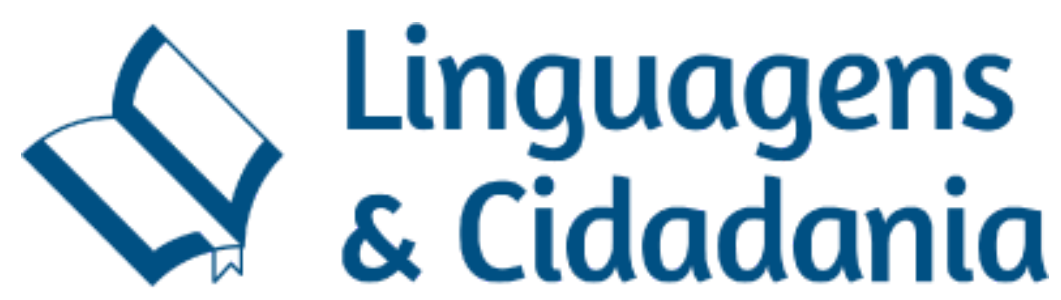

Entendemos que a análise que fizemos é um recorte, delimitado a partir de um olhar interpretativo. Assim, é possível que um outro analista, em outras condições de produção, trabalhe com o mesmo corpus e produza efeitos de sentido distintos. No nosso entender, esta dissertação possibilitou uma compreensão acerca da heterogeneidade do discurso de Dilma, destacando-se o forte embate de forças travado durante o processo de impeachment.

\section{REFERÊNCIAS}

AUTHIER-REVUZ, Jacqueline. Heterogeneidade(s) enunciativa(s). In: Cad. Est. Ling., Campinas, (19): 25-42, jul./dez. 1990.

Heterogeneidade mostrada e heterogeneidade constitutiva: elementos para uma abordagem do outro no discurso. In: Entre a transparência e a opacidade: um estudo enunciativo do sentido. Porto Alegre: EDIPUCRS, 2004.

CAZARIN, Ercília Ana. Heterogeneidade discursiva: relações e efeitos de sentido instaurados pela inserção do discurso-outro no discurso político de L. I. Lula da Silva. Ijuí: Ed. UNIJUÍ, 1998.

Identificação e representação política: uma análise do discurso de Lula (1978-1998); Tese (Doutorado em Letras) - Universidade Federal do Rio Grande do Sul, 2004.

COURTINE, Jean-Jacques. Análise do discurso político: o discurso comunista endereçado aos cristãos. São Carlos: EdUFSCar, 2009.

FOUCAULT, Michel. A arqueologia do saber. Tradução de Luiz Felipe Baeta Neves. $7^{\mathrm{a}}$ ed. Rio de Janeiro: Forense Universitária, 2008.

INDURSKY, Freda. Polêmica e Denegação: dois funcionamentos discursivos da negação. In: Cadernos de Estudos Linguísticos. Campinas, Vol. 19, jul./dez. 1990.

A memória na cena do discurso. In: Memória e história na/da Análise do Discurso. Org: Indursky, Freda; Mittmann, Solange; Ferreira, Maria Cristina. Campinas, Mercado das Letras, 2011.

A fala dos quartéis e as outras vozes. Tese de Doutoramento, Campinas, 1992, publicada pela Editora da UNICAMP, 2013. 


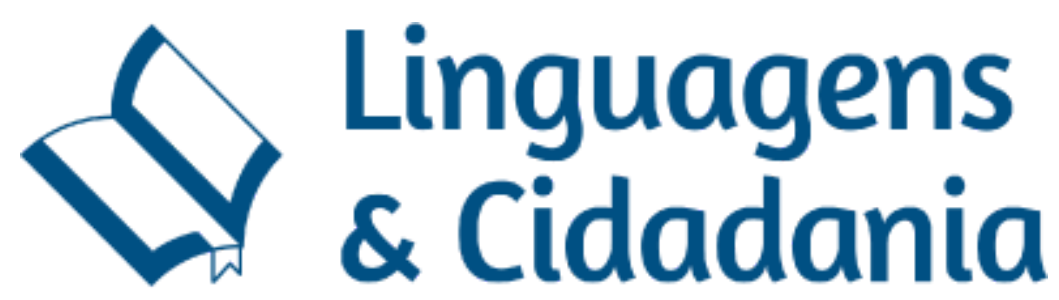

MITTMANN, Solange. Heterogeneidade constitutiva, contradição histórica e sintaxe. In: Desenredo: Revista do Programa de Pós-Graduação em Letras/ Universidade de Passo Fundo. Vol. 1, nº 1. Passo Fundo: Ed. Da Universidade de Passo Fundo, 2005.

ORLANDI, Eni, P. Terra à vista!: discurso do confronto: velho e novo mundo. São Paulo: Cortez: Editora da Universidade Estadual de Campinas, 1990.

PÊCHEUX, Michel. Semântica e discurso: uma crítica à afirmação do óbvio. $5^{\mathrm{a}}$ ed. Campinas, SP: Editora da Unicamp, 2014. 